Revista Temas Socio Jurídicos

Vol. 38 No 77 Julio - Diciembre de 2019

ISSN: 0120-8578

ISSN electrónico: 2590-8901

\title{
PERSISTENCIA DE FACTORES DE DISCRIMINACIÓN PRODUCTO DE LA ORIENTACIÓN SEXUAL: HACIA UNA GARANTÍA MATERIAL DEL DERECHO A LA IGUALDAD ${ }^{1 *}$
}

Martin Humberto Casadiegos Santana ${ }^{2 * *}$

Recibido: Mayo 27 de 2019

Aceptado: Noviembre 13 de 2019

\section{RESUMEN:}

El presente artículo de investigación se propone analizar el "principio de igualdad y no discriminación" ya no en los libros, sino en la práctica, en los hechos, a efecto de entrar a determinar cómo, a pesar de existir un amplio desarrollo internacional y nacional de los derechos de la población LGTBI, cuando se lleva al campo aplicado, encontramos la persistencia de factores de discriminación implícitos y explícitos, con origen en una orientación sexual diversa.

Citar este trabajo como: Casadiegos, M. (2019). Persistencia de factores de discriminación producto de la orientación sexual: hacia una garantía material del derecho a la igualdad. En: Temas Socio-Jurídicos, 38(77), pp. 65-92. DOI: https:// doi.org/10.29375/01208578.3631

1 * Artículo de investigación. Proyecto titulado: "El principio de igualdad y no discriminación como fórmula de protección constitucional de la población LGTBI en la Universidad Francisco de Paula Santander, Ocaña". EL PRINCIPIO DE IGUALDAD Y NO DISCRIMINACIÓN COMO FÓRMULA DE PROTECCIÓN CONSTITUCIONAL DE LA POBLACIÓN LGTBI EN LA UNIVERSIDAD FRANCISCO DE PAULA SANTANDER OCAÑA

$2{ }^{* *}$ Abogado, Especialista en Derecho Público, Máster en Derecho Constitucional y Derechos Humanos. Docente tiempo completo de la Universidad Francisco de Paula Santander, Ocaña. Docente investigador adscrito al Grupo de Investigación Socio Jurídico (GISOJU). Orcid: https://orcid.org/0000-0001-9112-1585 Correo electrónico: mhcasadiegoss@ufpso.edu.co. 
Para ello analizaremos los resultados producto de la aplicación de una encuesta como herramienta utilizada para la recolección de datos, los cuales se encuentran traducidos en veintiocho gráficos que ilustran los resultados recabados de una muestra de 1446 estudiantes universitarios, divididos en dos segmentos poblacionales en atención a la manifestación de su orientación sexual LGTBI o heterosexual.

Con ello buscamos determinar cómo, pese a existir un andamiaje jurídico de protección formal y jurídica del principio de igualdad y no discriminación, en el entorno social en el cual nos desarrollamos, se mantienen persistentemente factores de discriminación que atentan contra el principio de la igualdad material. Para ello realizamos un análisis crítico y reflexivo, partiendo del conocimiento de la norma internacional y constitucional, para desembocar en el contraste existente entre lo regulado y la realidad, apoyados en el derecho internacional y constitucional, así como en las evidencias obtenidas.

El método de investigación que se implementó en esta investigación es el de análisis- síntesis, a través del enfoque cualitativo.

Palabras clave: Discriminación; Derecho a la igualdad; orientación sexual; igualdad material; igualdad formal.

\title{
PERSISTENCE OF DISCRIMINATION FACTORS DUE TO SEXUAL ORIENTATION: TOWARDS A MATERIAL GUARANTEE OF EQUAL RIGHTS
}

\begin{abstract}
:
The purpose of this research paper is to analyze the "principle of equality and non-discrimination" not only in books, but in practice, in actions, in order to establish how, in spite of a global and national development of the LGBTI population's rights, when applied, we keep finding implicit and explicit discrimination factors due to diverse sexual orientation.

For that purpose, we analyzed the results obtained from a survey used as a tool to collect information, which are reflected in 28 graphs that depict the answers gathered from 1,446 university students divided in two population groups in view of their sexual orientation, either LGBTI or heterosexual.

Through this analysis, we aim to determine how, in spite of existing a legal framework that protects, formally and legally, the principle of equality and non-discrimination in the social environment in which we live, there are still permanent discrimination factors that infringe upon the principle
\end{abstract}


of material equality. To this effect, we performed a reflexive and critical analysis drawn upon the knowledge we have of the constitutional and international standard, in order to establish the existing conflict between reality and regulations, supported in the constitutional and international law, as well as the evidences obtained.

The research method applied during this study is the analysis-synthesis, using a qualitative approach.

Keywords: Discrimination; right of equality; sexual orientation; material equality; formal equality.

\section{PERSISTÊNCIA DE FATORES DE DISCRIMINAÇÃO DEVIDO À ORIENTAÇÃO SEXUAL: RUMO A UMA GARANTIA MATERIAL DO DIREITO A IGUALDADE}

\section{RESUMO:}

Este artigo de pesquisa pretende analisar o "princípio de igualdade e não discriminação" não mais nos livros, mas sim na prática, nas ações, para determinar como, apesar da existência de um amplo desenvolvimento internacional e nacional dos direitos da população lgtbi, quando levados para o campo aplicado, encontramos a persistência de fatores de discriminação implícitos e explícitos, originados em uma orientação sexual diversa.

Para isso, analisaremos os resultados da aplicação de uma enquete como ferramenta utilizada para a coleta de dados, traduzidos em 28 gráficos que ilustram os resultados obtidos de uma amostra de 1446 estudantes universitários, divididos em dois segmentos populacionais com base na manifestação de sua orientação sexual LGTBI ou heterossexual.

Com isso, buscamos determinar como, apesar da existência de um andaime jurídico de proteção formal e legal do princípio da igualdade e da não discriminação, no ambiente social em que nos desenvolvemos, persistem os fatores de discriminação contra o princípio da igualdade material. Para isso, realizamos uma análise crítica e reflexiva, baseada no conhecimento da norma internacional e constitucional, para levar ao contraste existente entre o regulamentado e a realidade, nos apoiamos no direito internacional e constitucional, bem como nas evidências obtidas.

O método de pesquisa implementado é análise-síntese, por meio da abordagem qualitativa.

Palavras-chave: Discriminação; Direito à igualdade; orientação sexual; igualdade material; igualdade formal. 


\section{INTRODUCCIÓN}

Hemos avanzado en la eliminación de barreras establecidas por factores diferenciadores de los individuos, siempre en la búsqueda de brindar mayor inclusión y consigo, la prohibición de cualquier forma de discriminación existente. En tal sentido, nuestros ordenamientos normativos se han venido nutriendo de principios que logran orientar desde la misma base normativa de los principios imperativos del ius cogens ${ }^{3}$ todos los ordenamientos constitucionales, pasando por leyes, decretos y reglamentos institucionales que deben acoplarse jurídicamente al cumplimiento de aquellos derechos inherentes al individuo.

Este catálogo de derechos no puede ser un conjunto de normas cerradas y aisladas, que permanecen petrificadas en el tiempo, como normas inalterables, sino que, por el contrario, deben ser entendidas e interpretadas como principios que irradian todo el ordenamiento jurídico, para su aplicabilidad.

La evolución normativa no solamente puede estar dada desde la norma imperante en un Estado, sino que además de ello todas las instituciones están llamadas a realizar los ajustes pertinentes, que les permitan garantizar una plena salvaguarda de los derechos de las personas bajo su amparo.

Desde la Constitución Política Nacional colombiana de 1991, se estableció en el artículo $13^{4}$ la consagración del principio de igualdad y no discriminación, como principio fundante de los derechos de todo individuo, que entre sus múltiples funciones orienta la consecución de otras normas reglamentarias al interior de un Estado y sus instituciones.

La Corte Constitucional colombiana ha venido realizando un desarrollo jurisprudencial para la salvaguarda del principio de igualdad y no discriminación en razón a la orientación sexual diversa, con el objetivo de brindarles una garantía plena a los derechos de las personas LGTBI, la cual, pese a encontrarse garantizada normativamente, carece de una garantía efectiva y material por nuestra sociedad, encontrando con ello la restric-

\footnotetext{
3 Párrafo No. 184. El principio de la protección igualitaria y efectiva de la ley y de la no discriminación constituye un dato sobresaliente en el sistema tutelar de los derechos humanos consagrado en muchos instrumentos y desarrollado por la doctrina y jurisprudencia internacionales. En la actual etapa de la evolución del derecho internacional, el principio fundamental de igualdad y no discriminación ha ingresado en el dominio del ius cogens. Sobre él descansa el andamiaje jurídico del orden público nacional e internacional y permea todo el ordenamiento jurídico (caso Yatama vs. Nicaragua, 2005).

4 Artículo 13. Todas las personas nacen libres e iguales ante la ley, recibirán la misma protección y trato de las autoridades y gozarán de los mismos derechos, libertades y oportunidades sin ninguna discriminación por razones de sexo, raza, origen nacional o familiar, lengua, religión, opinión política o filosófica. El Estado promoverá las condiciones para que la igualdad sea real y efectiva y adoptará medidas en favor de grupos discriminados o marginados. El Estado protegerá especialmente a aquellas personas que por su condición económica, física o mental, se encuentren en circunstancia de debilidad manifiesta
} 
ción de derechos fundamentales en el campo laboral, académico, acceso a servicios de salud, entre otros.

Pero, ¿qué pasaría si no existiera una institución garante de los derechos fundamentales de todo individuo, que logre en la medida de su función la protección de aquellos derechos reclamados y sometidos a su arbitrio?, ¿seguiríamos estableciendo barreras sobre factores diferenciadores? En razón de lo anterior, estamos llamados a establecer procesos de regulación normativa que propendan por garantizar los derechos de las personas, no solo desde un aspecto normativo sino también material.

La garantía material de los derechos es la verdadera brecha a superar como sociedad, ya que en la actualidad persisten patrones de discriminación en razón de género, posición social o económica, religión, discapacidad física o mental y orientación sexual. Pese a los esfuerzos realizados por parte de la comunidad internacional, los Estados, organizaciones gubernamentales y no gubernamentales, se ha logrado un amparo normativo, pero aún persiste la discriminación en nuestra sociedad.

El presente artículo se encarga de abordar el principio de la igualdad en personas LGTBI, tomando como muestra la población estudiantil de la Universidad Francisco de Paula Santander, Ocaña, a efectos de examinar la persistencia de factores de discriminación implícitos y explícitos subyacentes en la comunidad universitaria, a efectos de brindar una mirada más amplia frente a la eliminación de prejuicios.

\section{RESULTADOS}

\section{Principio de igualdad y no discriminación}

El artículo 1 de la Declaración Universal de los Derechos Humanos preceptúa que "Todos los seres humanos nacen libres e iguales en dignidady derechos $y$, dotados como están de razón y conciencia, deben comportarse fraternalmente los unos con los otros”, marcando la importancia en la inclusión del principio de igualdad y no discriminación como principio universal aplicable a todas las personas sin ningún tipo de diferenciación, incluidas aquellas que manifiesten una orientación sexual diversa.

Sobre la base de un conjunto de normas internacionales se ha construido un andamiaje jurídico que lleva a los Estados a promover una garantía efectiva de los derechos fundamentales en igualdad de condiciones en su aplicación y ejercicio, sin ningún tipo de discriminación. Pero esta labor debe ser emprendida subsidiariamente por todos los entes públicos y privados que deben estar en sintonía para salvaguardar los derechos humanos.

Por ello, la eliminación de barreras normativas o sociales, debe estar dada no solo desde el abordaje jurídico, sino que también debe estar acompaña 
de la observación y análisis de los diferentes comportamientos sociales que terminan generando discriminaciones implícitas en razón de los factores excluyentes.

La discriminación puede ser estudiada atendiendo a variadas circunstancias fácticas que permiten su valoración. De igual forma, la discriminación entra a ser definida de diferentes maneras, pero solo nos ocuparemos de aquella vista desde plano jurídico, entendiendo que "la discriminación es una limitación injusta a las personas en cuanto a sus libertades y protecciones fundamentales, a la participación social y política y a un sistema de bienestar adecuado a sus necesidades" (Cepeda, 2007). En igual sentido, la Organización de las Naciones Unidas, ve la discriminación como "situaciones de distinción, exclusión, restricción o preferencia que atentan (directamente o indirectamente) contra los derechos y la igualdad de oportunidades de las personas. Incluyen las respuestas y remedios del Estado" (Naciones Unidas, s.f.).

En toda sociedad encontramos posturas conservadoras, conceptos arraigados desde el binarismo de género "hombre-mujer", como el primer factor diferenciador de todo individuo, estableciendo sobre nosotros y acorde al sexo asignado al momento de nacer una identidad que a futuro puede llegar a desconocer otros aspectos diferenciadores, que nos sitúan por fuera de esa fórmula binaria, y en este mismo sentido, vamos creando normas que solamente buscan adecuarse a dicho binarismo.

Guasch (2007, citado en García, 2016), hace una clara reflexión frente a las desigualdades de género imperantes en nuestras sociedades y la mayor vulneración de derechos en las que se sumerge aquel individuo que se aparta de estos estándares sociales aceptados, afirmando que:

El hecho de tener que posicionarnos en sociedad como hombres o como mujeres sin ni siquiera haberlo elegido es injusto, ya que ambos géneros no cuentan con igualdad de oportunidades. Pero las desigualdades vinculadas al género no terminan ahí; si quienes se posicionan en una de esas dos categorías que cuentan con legitimidad en nuestra sociedad experimentan injusticias, quienes no encajan en una ellas las sufren aún más, ya que nuestra sociedad occidental neoliberal se sustenta en la heteronormatividad, caracterizada por el binarismo sexual y por el establecimiento de relaciones sentimentales monógamas, estables y tendentes a la reproducción y a la formación de familias (pp. 82-83)

En tal sentido, es claro que la simple consideración de encasillar a una persona en una categoría no aceptada por ella, impone cargas negativas que el individuo no está en la obligación de soportar, razón por la cual es necesario que la norma y el actuar de la sociedad estén en clara sintonía de inclusión frente a manifestaciones de diversidad sexual. 


\section{DIVERSIDAD SEXUAL}

Nuestro mundo está fabricado y estructurado en la diversidad de colores, olores y texturas que, conjugados todos sobre un objeto, un ser y un individuo, lo hacen verdaderamente particular. En este mismo sentido, debemos entender las diferencias sexuales que podemos encontrar en todos y cada uno de nosotros. La naturaleza nos reta a entender la amplia serie de preferencias sexuales que podemos encontrar en un grupo de personas, las cuales han venido pasando desde una esfera íntima y personalísima a convertirse en un tema público y aceptado, tomando distancia de aquellos patrones heterosexuales convencionales, para sumergirse en prácticas sexuales un poco más liberales, sin salir de una preferencia sexual heterosexual, como aquellas dadas por algunas parejas swingers. ${ }^{5}$

Ahora, si examinamos por fuera de la heterosexualidad, vamos a encontrar la atracción hacia parejas del mismo género (lesbianas, gay), ${ }^{6}$ e incluso personas que pueden llegar a manifestar atracción hacia personas de los diferentes géneros sin tener en cuenta sus preferencias sexuales (bisexual). En tal sentido, vamos a encontrar diferencias sustanciales que nos permitirían identificar una amplia gama de preferencias sexuales como una paleta de colores.

Por ello nos enfrentamos a retos constantes que nos deben llevar a la desestigmatización y eliminación de barreras jurídicas y sociales incrustadas en nuestros entornos, que limitan el libre desarrollo del individuo, impidiendo el acceso en igualdad de condiciones al ejercicio libre de la persona que busca ser lo que su interior quiere y no lo que la sociedad impone. Y es allí donde el debate académico toma importancia en la medida en que logra descomponer aquellos estereotipos sociales preconcebidos, para dar mayor garantía material o real a principios como el de "la igualdad y no discriminación":

Desde esta perspectiva, para los estudios sobre diversidad sexual, la "sexualidad" y "la diversidad" constituyen categorías de análisis centrales. Así, la categoría "diversidad sexual" abarca las sexualidades plurales, polimorfas y placenteras como la homosexualidad, el lesbianismo, la bisexualidad y el transgénero (travestíes y transexuales), ya sea como identidades esencializadas o como prácticas sexuales sin ca-

5 La palabra swinger alude a "oscilar", "hamacarse", "ir y volver", y remite al intercambio sexual de parejas con pleno consentimiento de los partenaires y necesariamente en su presencia. Quienes adhieren a esta modalidad sexual como una práctica frecuente constituirían una subcultura sexual minoritaria configurada como un estilo de vida" (Orejuela, Piedrahita y Renza, 2011).

6 Actualmente, "tenemos, por un lado, los términos 'lesbiana' y 'gay' para designar distintos tipos de estilos de vida, sexualidades, prácticas sexuales, comunidades, asuntos, publicaciones y discursos; y por otro, la frase 'gay y lesbiana' o, más frecuentemente, “lesbiana y gay' (las damas primero)" (Reyes, 2010). 
rácter identitario. Pero no se quedan ahí; también incluyen el estudio de la heterosexualidad, pues aunque constituye la expresión de la sexualidad legitimada por excelencia, no por ello deja de ser otra de las formas en que la diversidad sexual se manifiesta. (Cruz, 2004, p.22)

La Corte Constitucional colombiana ha venido gestando línea jurisprudencial frente al reconocimiento de los derechos de las personas LGTBI, desde los inicios de la Corte con la sentencia T-594 de $1993^{7}$ con ponencia del Magistrado Dr. Vladimiro Naranjo Mesa, llegando hasta la sentencia T-283 del $2016^{8}$ con ponencia de la Magistrada Dra. Gloria Stella Ortiz Delgado, reconociendo y garantizando derechos fundamentales en temas como la unión marital de hecho, registro civil de las personas, privacidad y protección de datos, personas privadas de la libertad, pensiones, migración, matrimonio, derechos patrimoniales, adopción, educación y por supuesto, abordando el tema de la discriminación frente a comunidades o personas LGTBI a través de las sentencias T-152 del 200, T-492 del 2011, T-734 del 2011 y la sentencia T-909 del 2011, donde la Corte Constitucional ha manifestado frente a la diversidad sexual que:

La orientación sexual diversa, como expresión de la orientación sexual propia de la especie humana, se garantiza en la Constitución desde tres perspectivas: i) como contenido que ampara la libre disposición, artículos $1^{\circ}$, es decir, ingrediente de la dignidad humana como fundamento del Estado social de derecho, $5^{\circ}$, derecho inalienable de la persona, $15^{\circ}$, derecho fundamental de la esfera más íntima del sujeto, $16^{\circ}$, marca nuclear del libre desarrollo de la personalidad; ii) como contenido igualitario y no discriminatorio, artículos $5^{\circ}$ y $13^{\circ}$, para un reconocimiento de tales derechos y un trato igual ante una diversidad personalísima que no amerita regulación diferenciada y que sí lo hace una protección especial por ser sujeto sometido a condiciones de debilidad manifiesta; iii) como obligaciones reflejas, el mandato de acción negativa o de no interferencia y el mandato de acción positiva de especial protección, artículos $2^{\circ}, 5^{\circ}$, $6^{\circ}$, en cuanto parte de los fines esenciales del Estado, de su razón de ser y fundamento de sus reglas. (Sentencia T-909/11, 2011)

7 A través de la sentencia T-594 de 1993, el peticionario solicitó vía acción de tutela que se modificara su registro civil, sustituyendo su nombre de Carlos Montaño Díaz por el de Pamela Montaño Díaz, para efectos de fijar su propia identidad, en amparo de los derechos fundamentales a la igualdad y al reconocimiento de la personalidad jurídica, consagrados en los artículos 13 y 14 de la Constitución Política de Colombia.

8 En la sentencia T-283 del 2016, el peticionario indica que es bisexual, víctima del conflicto armado interno y que pertenece a la comunidad indígena uitoto del Amazonas, quien solicita mediante acción de tutela ser reubicado en una celda, con personas de su misma condición sexual, "al considerar vulnerados sus derechos fundamentales a la libertad de expresión y a la vida digna, así como al reconocimiento y debida protección de la diversidad étnica y cultural de los pueblos indígenas, y de las personas pertenecientes a la comunidad LGBTI. Tal violación surgió del alegado maltrato moral y psicológico que recibe el accionante de personas de la referida comunidad, e incluso de las autoridades del establecimiento carcelario". 


\section{La igualdad formal frente a la igualdad material}

La igualdad formal es aquella entendida como la igualdad dada a todo individuo en la aplicación imparcial de la norma, sin ningún trato diferenciador y atendiendo el principio de universalidad en el acceso a un sistema judicial capaz de salvaguardar derechos y hacer exigibles las obligaciones sin ninguna consideración particular más allá de las establecidas en el imperio de la ley. Esta construcción normativa está dada en los Estados liberales y democráticos, que establecen desde su Carta Magna, una protección especial al principio de igualdad como derecho inherente de todo individuo, estableciendo una clara relación en el reconocimiento del derecho sobre la norma positiva, basados en el principio de legalidad.

Prima facie es necesaria la existencia de normas garantes del derecho a la igualdad, a efectos de brindar mayor seguridad jurídica frente a goce pleno y efectivo de los derechos, pero no basta con la salvaguarda jurídica, ya que lo realmente importante es el comportamiento social en la aplicación real de la igualdad en nuestra sociedad. De nada nos sirve un sistema con garantías jurídicas, cuando seguimos generando prácticas discriminatorias y estableciendo barreras sociales que impiden el disfrute pleno de un derecho. En otras palabras, podríamos decir que en un Estado libre, democrático y pluralista, no es suficiente con la garantía formal o jurídica del derecho a la igualdad, sino que es indispensable la garantía formal o real, a efectos de lograr un trato idéntico de los individuos en circunstancias fácticas similares, apartado de cualquier criterio sospechoso. ${ }^{9}$

En este orden, la responsabilidad del Estado y sus diferentes instituciones no llega solo hasta la garantía legal del derecho, por ende debe extender su accionar hacia una garantía de hecho, con medidas educativas que permitan una desarticulación de aquellos factores que generen una discriminación implícita o explícita, no solo a nivel normativo, sino a nivel interpersonal, como una medida de garantía real del derecho a la igualdad.

Puesto que es un hecho que en toda comunidad se dan desigualdades sociales y económicas entre los individuos, una interpretación material del principio de igualdad supone la exigencia de que sea el Estado el encargado de hacer realidad este principio. No basta con que el Estado dicte normas no discriminatorias, sino que ha de adoptar medidas para conseguir la igualdad efectiva de todos los ciudadanos. (Cuenca, 1994)

Para la Corte Constitucional colombiana, el derecho a la igualdad reviste tres dimensiones, dentro de las cuales se analizan los criterios de igual-

9 En palabras de la Corte Constitucional, podemos decir que un criterio sospechoso es aquel establecido en relación con: "El sexo, la orientación sexual o la identidad de género; - La raza; - El origen nacional o familiar al igual que el étnico o de cualquier índole; - La lengua; - La religión; -La opinión política o filosófica; - La pigmentación o el color de la piel; La condición social y/o económica; - La apariencia exterior; - La enfermedad, la discapacidad o la pérdida de la capacidad laboral" (Corte Constitucional, 2011). 
dad formal, material y de la prohibición de no discriminación, fórmula que permite una garantía efectiva de los derechos de los individuos o colectivos sociales.

La igualdad es un concepto multidimensional, pues es reconocido como un principio, un derecho fundamental y una garantía. De esta manera, la igualdad puede entenderse a partir de tres dimensiones: i) formal, lo que implica que la legalidad debe ser aplicada en condiciones de igualdad a todos los sujetos contra quienes se dirige; y, ii) material, en el sentido garantizar la paridad de oportunidades entre los individuos; y, iii) la prohibición de discriminación que implica que el Estado y los particulares no puedan aplicar un trato diferente a partir de criterios sospechosos construidos con fundamento en razones de sexo, raza, origen étnico, identidad de género, religión y opinión política, entre otras. (Sentencia $\mathrm{T}-030 / 17,2017)$

\section{Persistencia de la discriminación en razón a la orientación sexual}

Es claro que, a nivel internacional y nacional, se ha propendido por crear un andamiaje normativo que busque la eliminación de cualquier forma de discriminación directa o indirecta, desde la base legal. Pe se a ello no han sido suficientes los esfuerzos realizados, ya que mantenemos en la actualidad posturas estigmatizantes que en nada contribuyen al desarrollo social de nuestras comunidades.

La investigación adelantada y aplicada en una comunidad universitaria buscó indagar acerca de posibles factores de discriminación persistentes en razón a la orientación sexual, sin medir otros criterios sospechosos como la raza, religión, discapacidad física o mental, etc.

Previa validación del instrumento (encuesta), se aplicó a una población muestra, en total de mil cuatrocientos cuarenta y seis (1446) estudiantes, con los resultados que expondremos a continuación bajo un análisis crítico de 28 gráficos, que traducen los resultados obtenidos. En este orden, se aplicaron 28 preguntas que recorren diferentes temas y las cuales analizamos comparativamente con base en 14 observaciones, acorde a las respuestas aportadas por parte de aquellas personas que se auto determinaron en la aplicación de la encuesta como LGTBI o heterosexuales. 


\section{P1}

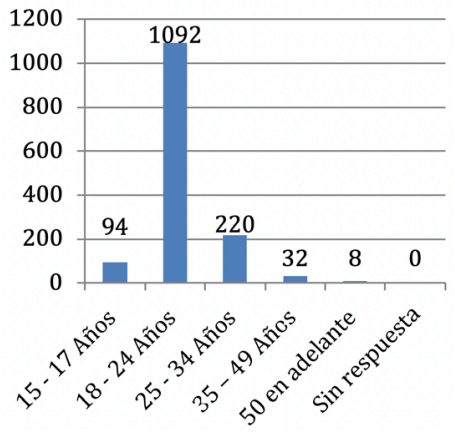

Figura 1. P-1.

Población total

Rango de edad

Fuente: Elaboración propia como resultados del proyecto de investigación titulado: "El principio de igualdad y no discriminación como fórmula para la protección constitucional de la población LGTBI en la Universidad Francisco de paula Santander Ocaña"

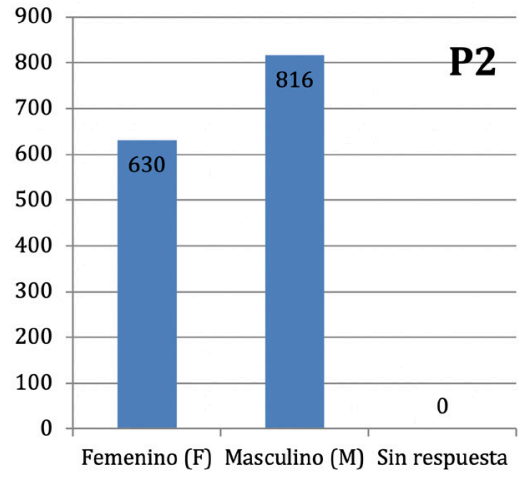

Figura 2. P- 2.

Población: Total.

Sexo registrado al nacer.

Fuente: Elaboración propia como resultados del proyecto de investigación titulado: "El principio de igualdad y no discriminación como fórmula para la protección constitucional de la población LGTBI en la Universidad Francisco de paula Santander Ocaña"

Observación 1. La muestra poblacional que realizó la encuesta está dentro de unos rangos edad predeterminados entre los 15 y 50 años, teniendo una población mayoritaria entre un rango de 18 a 24 años con un $75.52 \%$, seguidos de 25 a 34 años con un $15.21 \%$; de 15 a 17 años con un $6.50 \%$; de 35 a 49 años con un $2.21 \%$ y por último, la población mayor a 50 años con un $0.55 \%$, tal como se evidencia en la figura 1 . En la figura 2, establecemos el sexo registrado al nacer de los encuestados con un porcentaje de $56.43 \%$ que corresponde a población masculina y un $43.57 \%$ a femenina. 
Figura 3.P- 3.

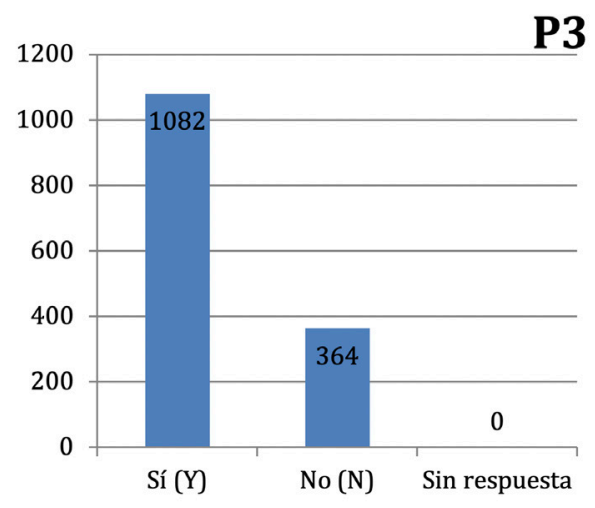

Población: Total. Pregunta:

¿Sabe usted qué es orientación sexual diversa?

Fuente: Elaboración propia como resultados del proyecto de investigación titulado: "El principio de igualdad y no discriminación como fórmula para la protección constitucional de la población LGTBI en la Universidad Francisco de paula Santander Ocaña"

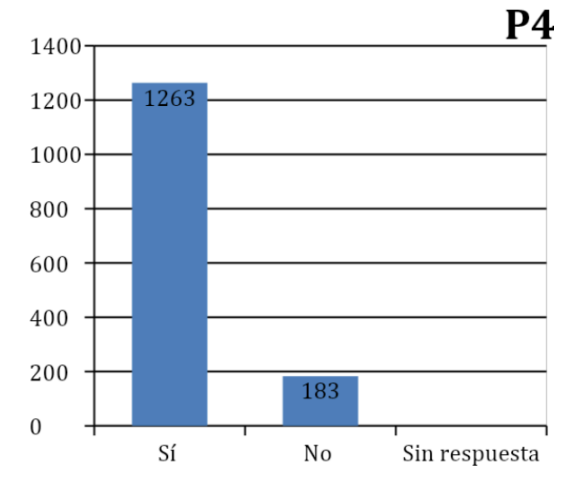

Figura 4. P-4.

Población: Total.

Pregunta: ¿Sabe usted qué significa la sigla LGTBI?

Fuente: Elaboración propia como resultados del proyecto de investigación titulado: "El principio de igualdad y no discriminación como fórmula para la protección constitucional de la población LGTBI en la Universidad Francisco de paula Santander Ocaña"

Observación 2. A efectos de evidenciar si los estudiantes universitarios tienen conocimiento frente a colectivos diferentes a los establecidos en la construcción binaria de hombre o mujer, se les preguntó acerca del conocimiento de la orientación sexual diversa (Figura 3) y el conocimiento de la sigla LGTBI (Figura 4). Se encontró que un $25.17 \%$ del total de la población encuestada no tiene referencia frente a la diversidad sexual, pregunta que es contrastada con la aplicada en la Figura 4, acerca del conocimiento del significado de la sigla LGTBI, en la que un porcentaje del $12.66 \%$ del total de la muestra manifiesta no tener conocimiento. Si 
bien encontramos una reducción porcentual del $12.51 \%$, se evidencia un porcentaje relativamente significativo de desconocimiento del significado de la diversidad sexual y LGTBI en la población universitaria.

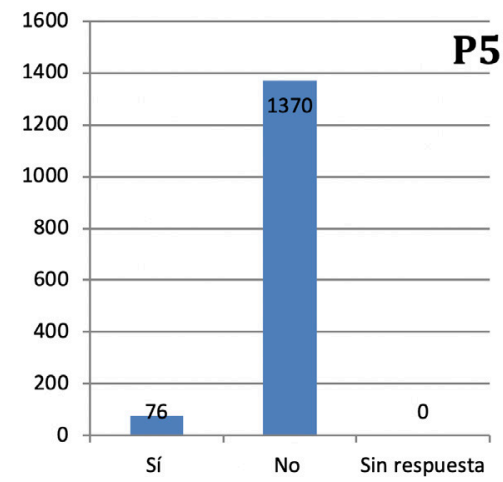

Figura 5. P-5.

Población: Total.

Pregunta: ¿Se auto-determina usted como una persona LGTBI?

Fuente: Elaboración propia como resultados del proyecto de investigación titulado: "El principio de igualdad y no discriminación como fórmula para la protección constitucional de la población LGTBI en la Universidad Francisco de paula Santander Ocaña"

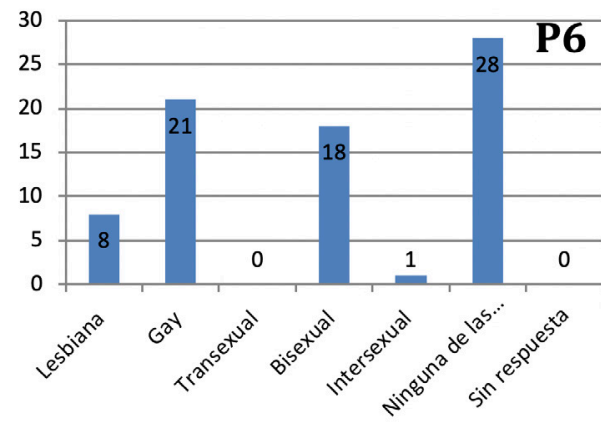

Figura 6.P-6.

Población: LGTBI.

Pregunta: ¿Cómo se identifica sexualmente?

Fuente: Elaboración propia como resultados del proyecto de investigación titulado: "El principio de igualdad y no discriminación como fórmula para la protección constitucional de la población LGTBI en la Universidad Francisco de paula Santander Ocaña"

Observación 3. Del total de población encuestada, un porcentaje del $5.26 \%$ se autodetermina como LGTBI, tal como lo muestra la figura 5, y de ellos un alto porcentaje, correspondiente al $36.84 \%$, no se identifica con algunos de los grupos de gay $(27.63 \%)$, bisexual (23.68\%), lesbiana $(10.53 \%)$ e intersexual $(1.32 \%)$. Este podría constituir un hecho relevante en la medida en que muestra la figuración de otras orientaciones diferentes a estos grupos de mayor presencia social (Figura 6). 
Figura 7.P-7.

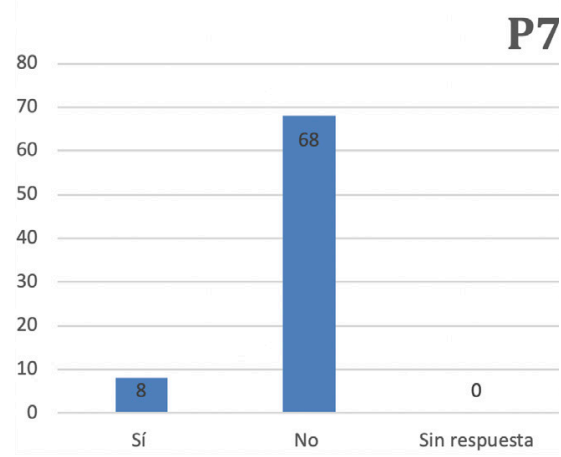

Población: LGTBI.

Pregunta: ¿Conoce usted alguna norma o acuerdo en la UFPSO que beneficie o proteja a una persona LGTBI?

Fuente: Elaboración propia como resultados del proyecto de investigación titulado: "El principio de igualdad y no discriminación como fórmula para la protección constitucional de la población LGTBI en la Universidad Francisco de paula Santander Ocaña"

\section{P8}

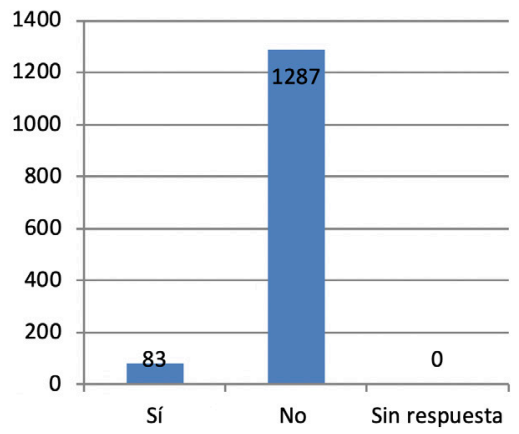

Figura 8.P-8.

Población: Heterosexual.

Pregunta: ¿Conoce usted alguna norma o acuerdo en la UFPSO que beneficie o proteja a una persona LGTBI?

Fuente: Elaboración propia como resultados del proyecto de investigación titulado: "El principio de igualdad y no discriminación como fórmula para la protección constitucional de la población LGTBI en la Universidad Francisco de paula Santander Ocaña"

Observación 4. La investigación adelantada busca medir también el nivel de conocimiento normativo al interior de la Universidad Francisco de Paula Santander, Ocaña. Para ello, se aplicó la misma pregunta para las personas que se autodeterminan como LGTBI (Figura 7) y aquellos que no (Figura 8), donde se encuentra un porcentaje mayoritario en los dos grupos con el $89.47 \%$ y $93.94 \%$, respectivamente, quienes manifestaron no conocer una norma o acuerdo en la UFPSO que beneficie, proteja a una persona LGTBI. En este orden, estaríamos frente a dos preguntas por 
resolver: a) la inexistencia de alguna norma, b) el desconocimiento de la norma, preguntas que resolvemos en observaciones siguientes.

Figura 9. P-9.

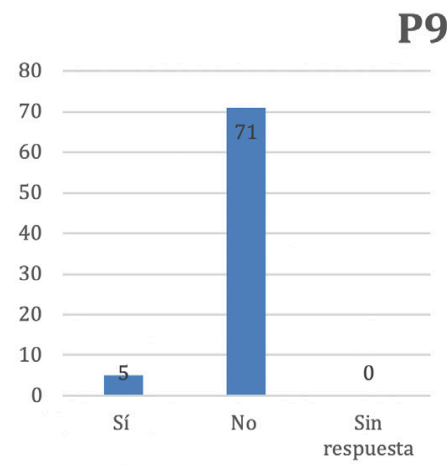

Población: LGTBI.

Pregunta: ¿Conoce usted alguna norma o acuerdo en la UFPSO que sancione prácticas discriminatorias en contra de una persona LGTBI?

Fuente: Elaboración propia como resultados del proyecto de investigación titulado: "El principio de igualdad y no discriminación como fórmula para la protección constitucional de la población LGTBI en la Universidad Francisco de paula Santander Ocaña"

P10

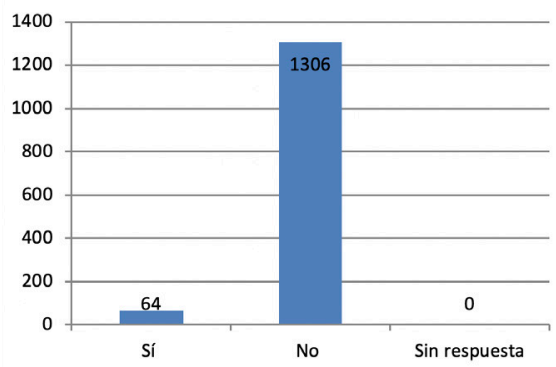

Figura 10.P-10.

Población: Heterosexual.

Pregunta: ¿Conoce usted alguna norma o acuerdo en la UFPSO que sancione prácticas discriminatorias en contra de una persona LGTBI?

Fuente: Elaboración propia como resultados del proyecto de investigación titulado: "El principio de igualdad y no discriminación como fórmula para la protección constitucional de la población LGTBI en la Universidad Francisco de paula Santander Ocaña"

Observación 5. En este mismo orden, se aplicó la pregunta a los dos grupos poblacionales diferenciados en la orientación y/o preferencia sexual, representada en las figuras 9 (LGTBI) y 10 (Heterosexual), en lo que concierne a el conocimiento de acuerdo o norma que sancione prácticas discriminatorias contra personas LGTBI, señalando el desconocimiento de norma o acuerdo con porcentajes del $93.42 \%$ y $95.33 \%$, marcando una mínima diferencia porcentual entre los dos grupos de un $1.91 \%$. 


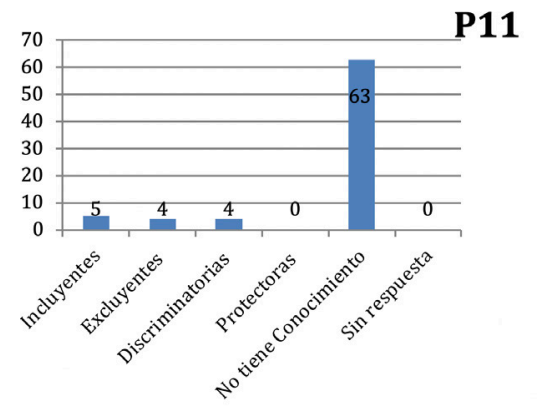

Figura 11.P-11.

Población: LGTBI.

Pregunta: ¿Cómo considera usted que son las normas, estatutos, acuerdos de la UFPSO, frente a la población LGTBI?

Fuente: Elaboración propia como resultados del proyecto de investigación titulado: "El principio de igualdad y no discriminación como fórmula para la protección constitucional de la población LGTBI en la Universidad Francisco de paula Santander Ocaña"

\section{P12}

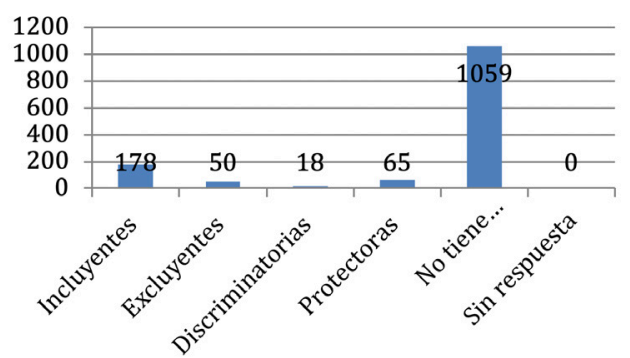

Figura 12.P-12.

Población: Heterosexual

Pregunta: ¿Cómo considera usted que son las normas, estatutos, acuerdos de la UFPSO, frente a la población LGTBI?

Fuente: Elaboración propia como resultados del proyecto de investigación titulado: "El principio de igualdad y no discriminación como fórmula para la protección constitucional de la población LGTBI en la Universidad Francisco de paula Santander Ocaña"

Observación 6. En este mismo orden y en total correlación con los porcentajes obtenidos en las preguntas anteriores, vemos cómo los estudiantes desconocen mayoritariamente y con un alto porcentaje si las normas son incluyentes, excluyentes, discriminatorias o protectoras de la población LGTBI. Con porcentajes alarmantes del $82.89 \%$ (Figura 11) y el $77.30 \%$ (Figura 12), manifiestan no tener conocimiento. 


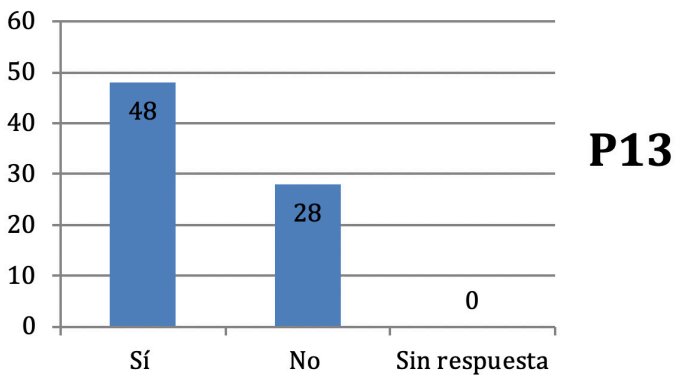

Figura 13.P-13.Población: LGTBI.

Pregunta: ¿Considera usted que existe discriminación producto de una orientación sexual LGTBI al interior de la UFPSO?

Fuente: Elaboración propia como resultados del proyecto de investigación titulado: "El principio de igualdad y no discriminación como fórmula para la protección constitucional de la población LGTBI en la Universidad Francisco de paula Santander Ocaña"

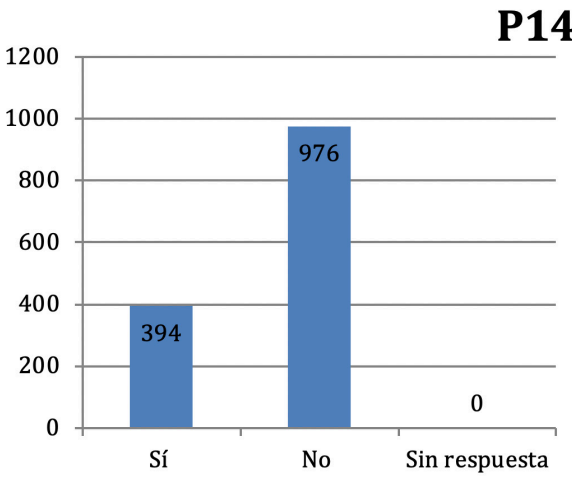

Figura 14.P-14.

Población: Heterosexual.

Pregunta: ¿Considera usted que existe discriminación producto de una orientación sexual LGTBI al interior de la UFPSO?

Fuente: Elaboración propia como resultados del proyecto de investigación titulado: "El principio de igualdad y no discriminación como fórmula para la protección constitucional de la población LGTBI en la Universidad Francisco de paula Santander Ocaña"

Observación 7. En la aplicación de esta pregunta vemos cómo existe una notoria diferencia entre lo que percibe aquel individuo de condición heterosexual y quien manifiesta una orientación sexual LGTBI. En este sentido, vemos como evidencia de forma diametralmente opuesta la discriminación en aquel que la soporta y en el que la percibe. Si vemos la Figura 13, donde la población muestra que corresponde a aquella que manifiesta ser LGTBI, encontramos que en un $63.16 \%$ frente al $36.84 \%$, las personas se sienten discriminadas en razón de su orientación sexual; 
por el contrario, de la población heterosexual que respondió la encuesta, solo un $28.76 \%$ considera que sí hay discriminación producto de la orientación sexual al interior de la universidad, frente a un $71.24 \%$ que no lo considera, tal como lo muestra la figura 14 .

En este sentido, realizamos algunas preguntas que nos pudieran orientar un poco más acerca de los motivos que una persona LGTBI tuviese para sentir que puede existir algún tipo de discriminación.

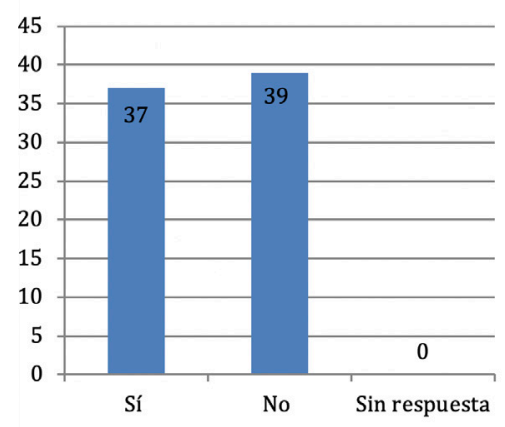

Figura 15.P-15.

Población: LGTBI.

Pregunta: ¿Usted expresa sin temor su orientación sexual y/o identidad de género al interior de la UFPSO?

Fuente: Elaboración propia como resultados del proyecto de investigación titulado: "El principio de igualdad y no discriminación como fórmula para la protección constitucional de la población LGTBI en la Universidad Francisco de paula Santander Ocaña"

P16

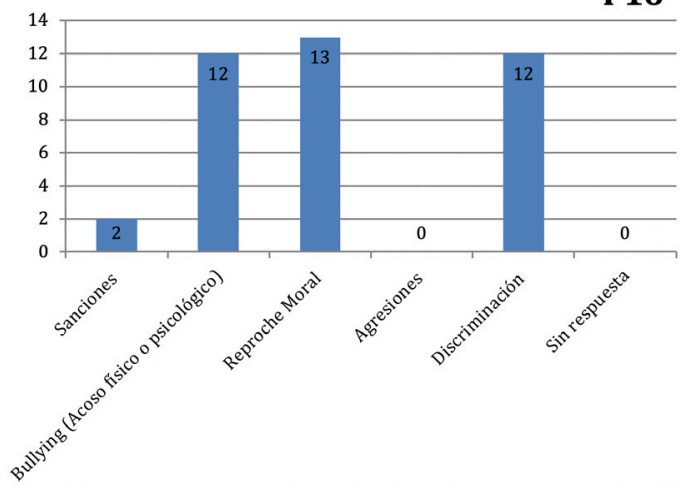

Figura 16.P-16.

Población: LGTBI.

Razones para no expresar su orientación sexual y/o identidad de género al interior de la UFPSO.

Fuente: Elaboración propia como resultados del proyecto de investigación titulado: "El principio de igualdad y no discriminación como fórmula para la protección constitucional de la población LGTBI en la Universidad Francisco de paula Santander Ocaña" 
Observación 8. En la figura 15, vemos los resultados de la pregunta ¿Expresa sin temor su orientación sexual y/o identidad de género al interior de la UFPSO?, en la cual un $51.32 \%$ expresa que siente temor y un $48.68 \%$ manifiesta que no siente temor. De esta manera, se indagó acerca de las razones para no manifestar su orientación de género y/o identidad de género (Figura 16), viendo como resultado que un $33.33 \%$ teme a un reproche moral, un $30.77 \%$ al bullying (acoso físico o psicológico), un $30.77 \%$ a la discriminación, un $5.13 \%$ a sanciones, y agresiones $0.00 \%$.

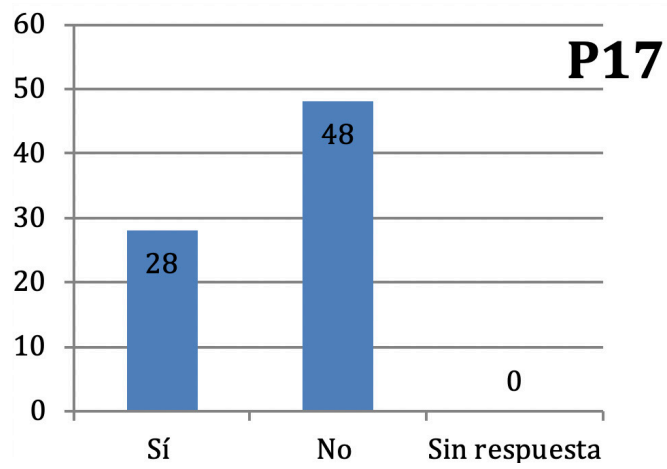

Figura 17.P-17.

Población: LGTBI.

Pregunta: ¿Se siente libre de tener manifestaciones de cariño y/o afecto en público (tomarse de la mano, besarse), al interior de la UFPSO?

Fuente: Elaboración propia como resultados del proyecto de investigación titulado: "El principio de igualdad y no discriminación como fórmula para la protección constitucional de la población LGTBI en la Universidad Francisco de paula Santander Ocaña"

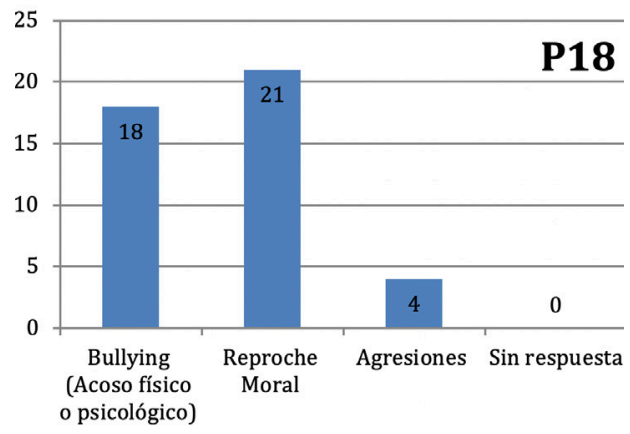

Figura 18.P-18.

Población: LGTBI.

Razones para no tener manifestaciones de cariño y/o afecto en público, al interior de la UFPSO.

Fuente: Elaboración propia como resultados del proyecto de investigación titulado: "El principio de igualdad y no discriminación como fórmula para la protección constitucional de la población LGTBI en la Universidad Francisco de paula Santander Ocaña" 
Observación 9. Igualmente, se preguntó a la población que manifestó autodeterminarse como LGTBI, si se siente libre de tener manifestaciones de cariño y/o afecto en público (tomarse de la mano, besarse) al interior de la UFPSO. Un $63.16 \%$ manifestó que NO y un $36.84 \%$ que SÍ, tal como podemos ver en la Figura 17. Dentro de las razones señaladas como motivación para no tener una manifestación de cariño en público son: reproche moral, 43.75\%; bullying (acoso físico o psicológico), $37.50 \%$; sanciones, $10.42 \%$; agresiones, $8.33 \%$.

El análisis que procederemos a hacer está focalizado a determinar si existe garantía real y efectiva del principio de igualdad y no discriminación de la población LGTBI al interior de la Universidad.

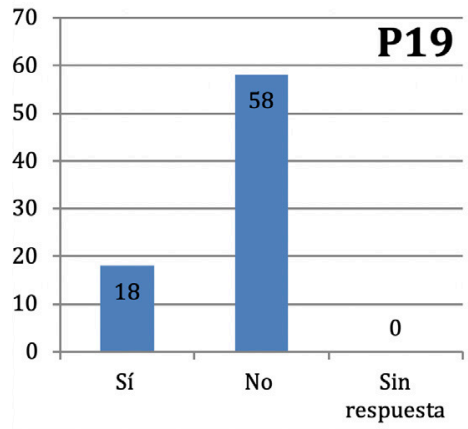

Figura 19.P-19.Población: LGTBI

Pregunta: ¿Alguna vez ha sido víctima de un acto de discriminación y/o violencia en contra de una persona LGTBI al interior de la UFPSO?

Fuente: Elaboración propia como resultados del proyecto de investigación titulado: "El principio de igualdad y no discriminación como fórmula para la protección constitucional de la población LGTBI en la Universidad Francisco de paula Santander Ocaña"

P20

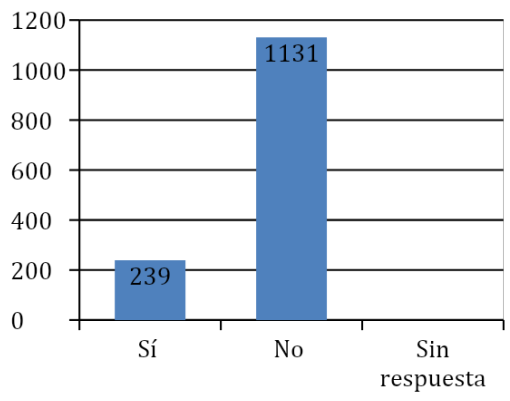

Figura 20.P-20.

Población: Heterosexual.

Pregunta: ¿Alguna vez ha observado un acto de discriminación y/o violencia en contra de una persona LGTBI al interior de la UFPSO?

Fuente: Elaboración propia como resultados del proyecto de investigación titulado: "El principio de igualdad y no discriminación como fórmula para la protección constitucional de la población LGTBI en la Universidad Francisco de paula Santander Ocaña" 
Observación 10. Siguiendo la misma dinámica aplicada en relación con la formulación de una pregunta similar a los dos grupos poblacionales objeto de la muestra (LGTBI-HETEROSEXUAL), preguntamos si habían sido víctimas (preguntado a población LGTBI - Figura 15) u observado (preguntado a población heterosexual - Figura 16). Se evidencia la persistencia de discriminación producto de la orientación sexual que aún no ha sido superada con porcentajes del $23.68 \%$ de quienes manifiestan haber sido víctimas y $17.45 \%$ de quienes han observado.

En este orden, nos permitimos indagar un poco más a profundidad en aquellas personas que afirmativamente manifiestan haber sido víctimas u observado cualquier tipo de discriminación al interior de la universidad, procediendo a formular tres (3) preguntas adicionales y complementarias, que me permitiré analizar a continuación.

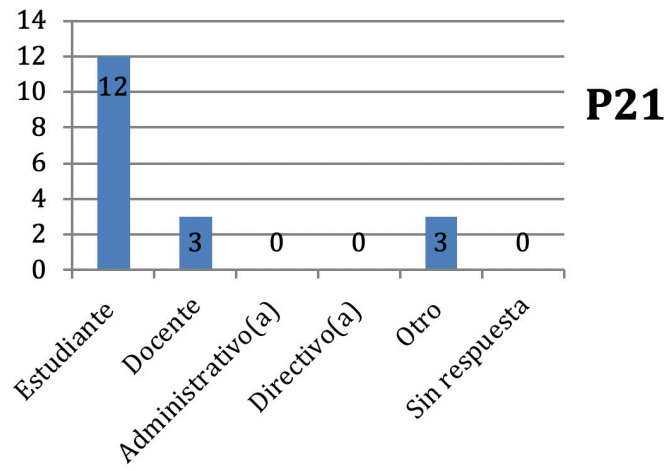

Figura 21.P-21.

Población: LGTBI.

Identifique al agresor.

Fuente: Elaboración propia como resultados del proyecto de investigación titulado: "El principio de igualdad y no discriminación como fórmula para la protección constitucional de la población LGTBI en la Universidad Francisco de paula Santander Ocaña"

Observación 11. Como lo relacionamos en la observación anterior, los gráficos 17 y 18, respectivamente, nos permiten identificar el agente que genera la conducta discriminatoria, encontrando que en los dos grupos poblacionales (LGTBI - Heterosexual), que el mismo cuerpo estudiantil es quien realiza mayores prácticas discriminatorias con un notable porcentaje del $66.67 \%$, seguido de Docentes con $16.67 \%$ y Otros con igual valor porcentual (Figura 17), esto frente a quienes manifiestan haber sido víctimas y en quienes han observado un acto de discriminación y/o violencia en contra de una persona LGTBI al interior de la UFPSO (Figura 18). El estudiante es quien presenta mayor porcentaje como agresor con un $80.75 \%$, seguido de Otros con $10.04 \%$, Docentes con $8.37 \%$ y Administrativos con el $0.84 \%$. 
Figura 22.P-22.

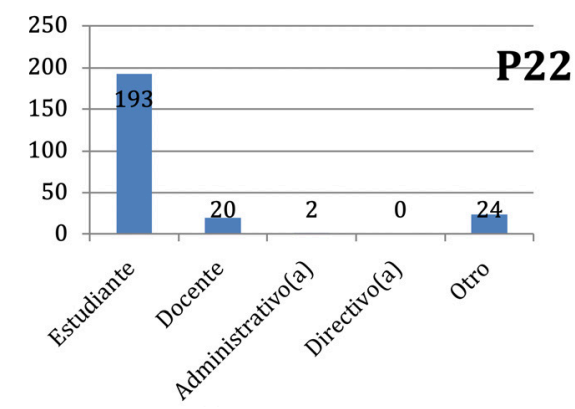

Población: Heterosexual.

Identifique al agresor.

Fuente: Elaboración propia como resultados del proyecto de investigación titulado: "El principio de igualdad y no discriminación como fórmula para la protección constitucional de la población LGTBI en la Universidad Francisco de paula Santander Ocaña"

Figura 23.P-23.

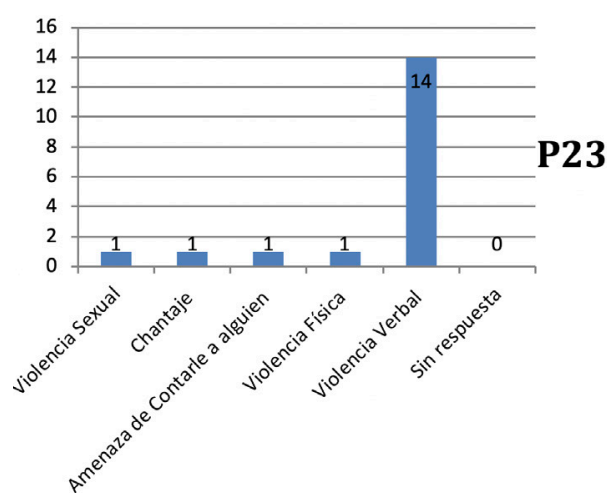

Población: LGTBI.

Identificación de la conducta.

Fuente: Elaboración propia como resultados del proyecto de investigación titulado: "El principio de igualdad y no discriminación como fórmula para la protección constitucional de la población LGTBI en la Universidad Francisco de paula Santander Ocaña"

Observación 12. En correlación al ciclo de preguntas aplicadas en las personas que manifestaron haber sido víctimas u observado un acto de discriminación y/o violencia en contra de una persona LGTBI al interior de la UFPSO, se indagó en las posibles conductas. Se encontró un alto porcentaje en los dos grupos poblacionales de la violencia verbal con un $77.78 \%$ (Figura 19) y $88.28 \%$ (Figura 20) respectivamente. Muy a pesar de que los porcentajes aplicados a otras conductas marcadas como discriminatorias son relativamente bajos frente a la violencia verbal, es necesario advertir que estas son conductas tipificadas en el ordenamiento penal, como el chantaje, la violencia física y la violencia sexual, las cuales 
no fueron puestas en conocimiento de ninguna autoridad competente al interior de la Universidad, tal como fue constatado por medio de entrevistas aplicadas a personal directivo de la institución, tema sobre el cual profundizamos en la investigación, pero no en el presente artículo.

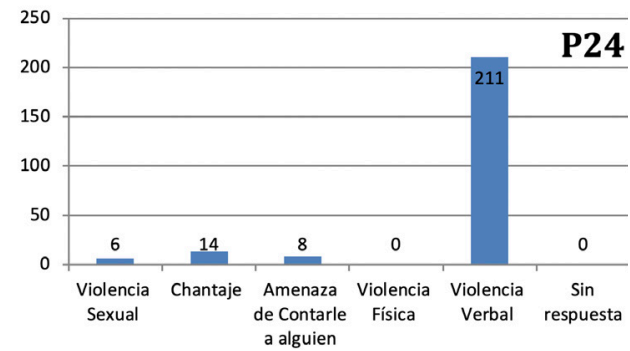

Figura 24.P-24.

Población: Heterosexual.

Identificación de la conducta.

Fuente: Elaboración propia como resultados del proyecto de investigación titulado: "El principio de igualdad y no discriminación como fórmula para la protección constitucional de la población LGTBI en la Universidad Francisco de paula Santander Ocaña"

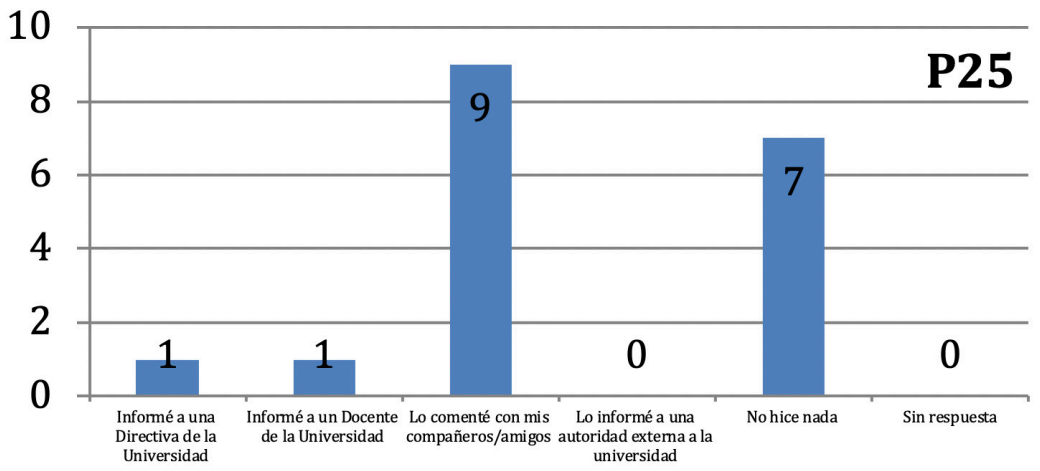

Figura 25.P-25.

Población: LGTBI.

Pregunta: ¿Qué acciones emprendió frente al hecho de violencia y/o agresión de la que fue víctima u observó?

Fuente: Elaboración propia como resultados del proyecto de investigación titulado: "El principio de igualdad y no discriminación como fórmula para la protección constitucional de la población LGTBI en la Universidad Francisco de paula Santander Ocaña" 


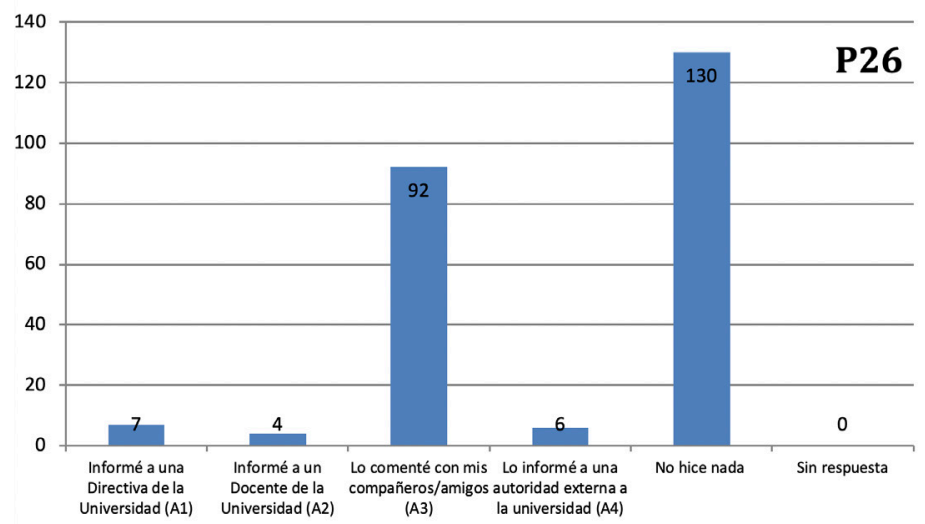

Figura 26.P-26.

Población: Heterosexual.

Pregunta: ¿Qué acciones emprendió frente al hecho de violencia y/o agresión de la que fue víctima u observó?

Fuente: Elaboración propia como resultados del proyecto de investigación titulado: "El principio de igualdad y no discriminación como fórmula para la protección constitucional de la población LGTBI en la Universidad Francisco de paula Santander Ocaña"

Observación 13. Si nos preguntáramos, ¿por qué no existe registro al interior de la universidad de alguna investigación o solicitud de investigación en trámite por hechos discriminatorios que en algunos casos rayan con la conducta penal? La respuesta la encontramos en las figuras 25 y 26 , en las que los porcentajes más altos están dados porque no se emprendió una acción efectiva para iniciar un proceso, como se puede constatar a través del instrumento aplicado. Quienes fueron víctimas se limitaron a comentarlo con un compañero, tal como lo muestra la figura 21, con un porcentaje del $50.00 \%$, seguido de "no hice nada" con un $38.89 \%$. La suma de estos dos valores equivale a un $88.89 \%$ de personas que se consideraron víctimas de una discriminación en razón a su orientación sexual y no realizaron ninguna acción efectiva frente a la vulneración de sus derechos. En igual sentido, las personas que observaron de la población de heterosexuales tampoco emprendieron una acción efectiva frente a la vulneración del derecho ("no hice nada", 54.39\%; "lo comenté con mis compañeros”, 38.49\%) (Figura 26). 


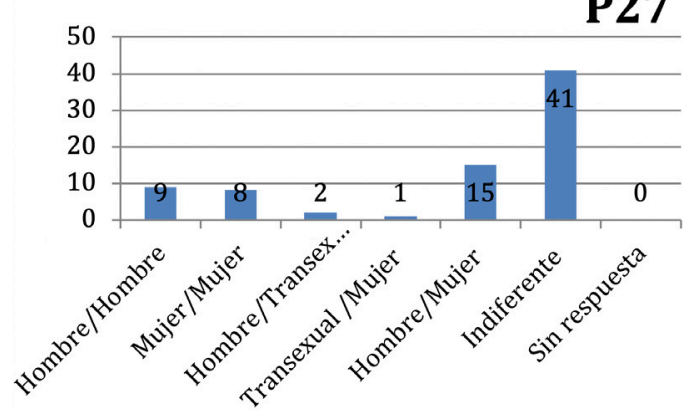

Figura 27.P-27.

Población: LGTBI.

Pregunta: ¿Frente a una manifestación de cariño y/o afecto al interior de la UFPSO, cuál de las siguientes parejas le representaría mayor agrado visual?

Fuente: Elaboración propia como resultados del proyecto de investigación titulado: "El principio de igualdad y no discriminación como fórmula para la protección constitucional de la población LGTBI en la Universidad Francisco de paula Santander Ocaña"

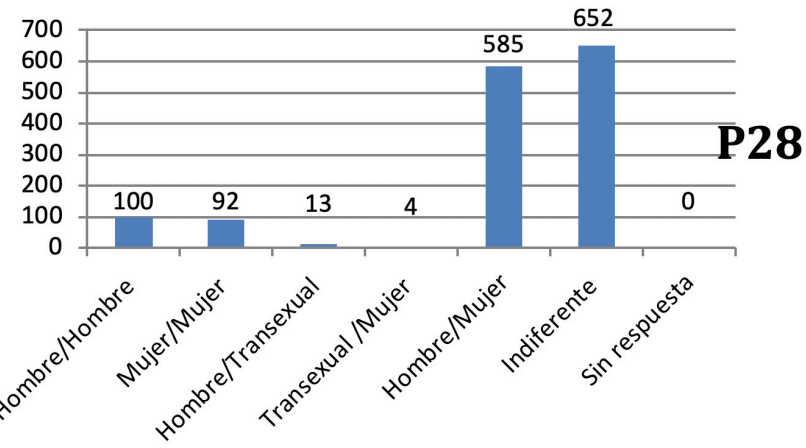

Figura 28.P- 28.

Población: Heterosexual.

Pregunta: ¿Frente a una manifestación de cariño y/o afecto al interior de la UFPSO, cuál de las siguientes parejas le representaría mayor agrado visual?

Fuente: Elaboración propia como resultados del proyecto de investigación titulado: "El principio de igualdad y no discriminación como fórmula para la protección constitucional de la población LGTBI en la Universidad Francisco de paula Santander Ocaña"

Observación 14. a efectos de indagar un poco frente aquellos factores de discriminación subyacentes en toda sociedad y que en algunos casos resultan ser imperceptibles, les preguntamos, frente a una manifestación de cariño, cuál pareja les representaba mayor agrado visual. La pregunta fue aplicada a quienes se autodeterminan como población LGTBI (Figura 27) o como población heterosexual (Figura 28). La población LGTBI manifestó que le resulta "indiferente" con un $53.55 \%$, seguido de la pareja "hombre/mujer" con un $19.74 \%$, "hombre/hombre" con un $11.84 \%$, "mujer/mujer" con un 10.53\%, "hombre/transexual" con un $2.63 \%$ y 
finalmente "mujer/transexual" con un $1.32 \%$. En este orden, la población heterosexual manifestó que le resulta "indiferente" con un $45.09 \%$ seguido de la pareja "hombre/mujer" con un $40.46 \%$, "hombre/hombre" con un $6.92 \%$, "mujer/mujer" con un $6.36 \%$, "hombre/transexual" con un $0.90 \%$ y finalmente, "mujer/transexual" con un $0.28 \%$.

En este sentido, debemos observar que tanto la población que se autodetermina como LGTBI como la heterosexual, mantiene la misma correlación frente a aquellas parejas que le representan mayor agrado visual, tal como está descrito en el párrafo anterior. Sin embargo, notamos que mientras en el grupo poblacional LGTBI, la diferencia porcentual entre quienes les resulta "indiferente" con la pareja "hombre/mujer", es de un $33.81 \%$, en el grupo poblacional heterosexual este porcentaje es mucho menor es un $4.63 \%$.

\section{CONCLUSIONES}

Cuando formulé la presente investigación, entendí la complejidad del tema, por las fibras íntimas que pudiese llegar a tocar y los prejuicios existentes en una sociedad conservadora como la nuestra, en donde, pese a estar en un ambiente más liberal y abierto al cambio generacional, como lo es la universidad, se siguen manteniendo apegos "moralistas" irracionales, muy ligados a los ambientes familiares y seguramente religiosos.

Normalmente como individuos racionales, asumimos conductas que desdicen de nuestra racionalidad, toda vez que orientamos nuestro conocimiento y actuar a la aplicación de prácticas sociales, la gran mayoría de ellas aceptadas, que terminan generando un proceso de estigmatización progresivo que genera graves consecuencias a mediano y largo plazo.

Históricamente, hemos utilizado muchos términos asociados a la orientación sexual que resultan peyorativos y que son empleados con el ánimo de segregar, mofar e insultar a un individuo, bien pueda ser o no que se autodetermine bajo una orientación sexual diversa, y procedemos, sin ningún reparo, a estampar un estigma social implícito o explícito.

La investigación adelantada da muestra de que existe en este entorno educativo una falta de empoderamiento de los derechos ligados a los colectivos LGTBI, quienes al igual de aquellas personas que se determinaron como heterosexuales desconocen totalmente la existencia de normas, bien para proteger o para sancionar conductas discriminatorias. En tal sentido, es claro que no basta con la existencia de la norma, cuando esta se desconoce, ya que, si el derecho está garantizado, pero desconozco su existencia, no podría hacer valer mis derechos. Pero si conozco mis derechos, pero estos no están regulados, puedo exigir su implementación.

Es claro que existe una plena y total salvaguarda del principio de igualdad y no discriminación aplicado a poblaciones LGTBI en Colombia, pero este 
avance normativo dista mucho de la garantía material que debe existir, toda vez que estos colectivos LGTBI que históricamente han sido marginados, se siguen considerando discriminados en razón a su orientación sexual, lo que impide el pleno goce de sus derechos fundamentales. En la encuesta aplicada, un $63.16 \%$ de la población LGTBI considera que existe discriminación al interior de la Universidad.

En este orden de ideas, se evidencia que existe temor para la realización de muestras de cariño y afecto en igualdad de condiciones a una pareja heterosexual. Al preguntarles si expresan sin temor su orientación sexual y/o identidad de género, un porcentaje del $63.16 \%$ manifiesta temor en razón a tener que enfrentar reproche moral, acoso físico o psicológico e incluso agresiones.

El artículo 13 de la Constitución Política de Colombia garantiza el derecho a la igualdad y no discriminación y, en igual sentido, la Ley 1482 del 2011, sanciona penalmente actos de discriminación por razones de raza, etnia, religión, nacionalidad, ideología política o filosófica, sexo u orientación sexual, discapacidad y demás razones de discriminación(negrillas y subrayas mías). Sin embargo, como lo venimos esbozando en líneas anteriores, las garantías jurídicas están dadas, ahora debemos comenzar a eliminar todas aquellas barreras discriminatorias que impiden una verdadera garantía material del derecho a la igualdad. Cambio que debe estar dado desde una garantía de goce efectivo de derechos hasta una lengua incluyente.

\section{REFERENCIAS BIBLIOGRÁFICAS}

Cepeda, J. R. (2007). ¿Qué es la discriminación y cómo combatirla? México: Consejo Nacional para la Discriminación

Cruz, G. C. (2004). Sexualidades diversas: Aproximaciones para su análisis. México: Editorial Miguel Ángel Porrúa.

Corte Constitucional Colombiana. (2017, 24 de enero). Sentencia T-030/17, Expediente T- 5.751.966. Recuperado de: http://www. corteconstitucional.gov.co/relatoria/2017/T-030-17.htm

Corte Constitucional Colombiana. (2011, 4 de mayo). Sentencia T-314/11, Referencia: expediente T-2643229. Recuperado de: http://www. corteconstitucional.gov.co/relatoria/2011/t-314-11.htm

Corte Constitucional Colombiana, 2011). Sentencia T-909/11. Recuperado de: http://www.corteconstitucional.gov.co/ relatoria/2011/t-909-11.htm

Corte Interamericana de Derechos Humanos (2005, 23 de junio). Caso Yatama vs. Nicaragua, Sentencia de 23 de Junio de 2005. Recuperado de: http://www.corteidh.or.cr/docs/casos/articulos/ $\underline{\text { seriec } 127 \text { esp.pdf }}$ 
Cuenca, E. C. (1994). El principio de igualdad material en la jurisprudencia del tribunal constitucional. Revista de Estudios Políticos, 0 (84) p.269. Recuperado de. https://recyt.fecyt.es/index.php/RevEsPol/article/ view/46902

García, G. C., \& Gutiérrez, M. P. (2016). La Diversidad de Género en la Escuela Pública y la exclusión que produce el binarismo. Revista interuniversitaria de formación del profesorado, 85 (30.1), pp 82-83

Guasch, O. (2007). La crisis de la heterosexualidad. Barcelona: Laertes.

Lambda Legal - Abogando por la igualdad. (s.f). Conceptos básicos sobre ser lesbiana, gay, bisexual, transexual o transgénero (lgbtt, por sus siglas). Recuperado el 18 de mayo de 2019 de https://www. lambdalegal.org/es/know-your-rights/article/jovenes-conceptos

Naciones Unidas. (2014.). Oficina del Alto Comisionado de las Naciones Unidas. Recuperado el 16 de mayo de 2019 de http://acnudh.org/ temas-de-ddhh/discriminacion/

Orejuela, O. J., Piedrahita, J. J., y Renza, F. (2011). La práctica/estilo de vida swinger: ¿una práctica social-sexual perversa? Sexualidad, salud $y$ sociedad, (10), p.40.

Reyes, M. L. (2010). Florilegio de deseos: nuevos enfoques, estudios y escenarios de la disidencia sexual y genérica. Iztapalama, México: Ediciones y Gráficos Eón. 